\title{
Research on Vocational Student Personalized Learning Recommended Model
}

\author{
Yinghua Zha ${ }^{1, a}$, Qishen Zhu ${ }^{1, b}$ \\ ${ }^{1}$ School of Computer and Software, Nanjing Institute of Industry Technology, Nanjing, China \\ azhayh@niit.edu.cn, bzhuqs@niit.edu.cn
}

Keywords: resource overload; collaborative filtering; learning progress predictive; e-learning model; personalized learning

\begin{abstract}
With the rapid development of Internet technology, E-learning as a new learning model has been favorable for most higher education, but the overload problems for network learning resources make students difficult to get more available learning resources. This paper discusses the characteristics of vocational students. This paper describes relationship between students and learning resources based on the collaborative filtering, learning progress and forecast recommendation algorithm. This paper presents a personalized learning recommendation models, so that the students could easy extend and migrate expertise to get in personalized learning. At last the optimization models for recommendation algorithms and feedback data are proposed.
\end{abstract}

\section{Introduction}

With the development of Internet technology, the network has become very popular in the people's daily work, study and daily life. It is changing the people learning way. The information technology and network-based learning environment make people get new online information easy, provide the basic hardware for online learning also. Now the mobile learning, ubiquitous learning, virtual learning and other learning models have been derived from online learning. With the popularity of smart mobile devices, the M-Learning is becoming more and more popular. Online learning is different from traditional classroom learning in providing learning resources methods, so that students can learn with their own ways and progresses anywhere anytime to become truly "learner-center" learning [1].

At present, the rapid development of the Internet makes digital educational environment radically improved, there are many online educational resources and online education projects, but the learners according to their own learning demands get valuable information more difficultly, so there are many serious "information overload" problems. The "information overload" makes the online educational resources can be used very small and affect learners online learning experiences. The personalized recommendation systems are the useful methods for different types of students in "information overload". In this paper, a learning process analysis and context-awarded online learning model is proposed for the characteristics of higher vocational students and "information overload" problems. In this model, the online learning resources can be recommended to different student by their characteristic value. A new online learning model is explored for higher vocational students in this paper.

\section{Online Learning Overview}

In recent years, online educational resources increase quickly with the development of cloud computing and network technologies in the elementary education (K-12 education), vocational skills and higher education. There are many learning platforms for online courses such as Coursera, NetEase Cloud Classroom and MOOC China. Online learning resources can be presented by many ways including audio, animation, and video and so on in addition to various types of text. The higher 
vocational students enjoy video learning resources mostly in the survey for online learning. The video presentation is better than boring texts because it is easy to accept and learn.

Online Learning Concept. Online learning known as E-learning is the way for learners to get learning resources using the information environment including network communications, computers and multimedia technologies and so on. It is a learning process also to help learners realize teacher-student interaction, construct personal knowledge. That is to say, online learning is a new learning model to help learners obtain education information, resources and services using modern information technologies and network technologies. This is the main teaching methods of modern remote education, and the learners can truly realize "Anyone, Anytime, Anywhere, Anystyle (4A)" self-learning.

Online Learning Development. With the development of Internet technologies, remote education not only become popular, but also affects the higher education. Since Stanford University launched a "massive open online course" (abbreviated: MOOCs) in 2011, more and more universities have offered high-quality network open courses, have provided a low-cost learning opportunities. So anyone can sign up to get online courses to learn if they have willingness to learn and there are some network conditions. There are massive learning resources, large-scale distributed learning partners, diversified distributed network learning types, good support services, openness, self-organization, sociality and so on in MOOC projects. There are many most famous MOOC platforms including Coursera, edX and Udacity [2].

The teaching projects of MOOC courses are broken down into small pieces, courses are fragmented, and short video records are made for knowledge points. These video courses are almost within 5-15 minutes, so students can learn online anytime, anywhere easily. Meanwhile these projects can embed some questions in the students learning processes; this can make the learners interesting and make the learning efficient. At the same time, these platforms can provide real-time discussion to facilitate online communication.

This new learning model gives students new contextualized learning experiences. It implements teaching processes in these E-learning platforms with teaching, learning, practice, assessment, measurement, collaboration, communication, etc. Students can not only learn fragmentation of knowledge online anywhere, according to their ability, choose and customize their learning units, but also they can evaluate their learning outcomes through online quizzes, assignments, etc. Meanwhile the students can make up learning groups all over the world; this can improve students' interesting in learning, self-learning abilities and learning effects greatly.

\section{Analysis of Vocational Education Online Learning Feature}

Higher Vocational Education Features. Higher vocational education is an important branch of higher education in order to train students for strong practical abilities and make them have higher qualified technologies. This education focuses on the development of skills and practical abilities in professional subjects setting and teaching and the application of knowledge and practice. So it is more important than normal higher education. Compared to secondary education, higher vocational education is no longer cultural lessons but professional subjects' courses. Students at higher vocational education process study professional subjects which select by themselves, they not only need to master knowledge about their select, but also need to develop their ability to solve practical problems about expertise areas, so the higher education stage learning model should have autonomy, initiative and applied [3].

University is a semi-opening learning environment, the form of professional courses and university student management give students a lot of freedom to learn their technologies, students have abundant free time can be used after class. They need look up information, read professional books and other independent learning ways to build the profession knowledge architecture. Online E-learning can not only help students to effectively understand curriculum knowledge, but also train students self-learning and self-learning ability. Online learning platforms also can record these steps for skills 
training and these processes of resolving difficult problems to help students master professional courses knowledge after class further.

Online Learning Application Basis of Higher Vocational Education. With the state investment for the construction of higher vocational colleges, the Ethernet coverages almost campus in China, as well as many computing centers and data centers are established, this provides good networks, servers, storages and other hardware environment for online learning. Good network signal bandwidth and storage space make upload and download online learning resources more conveniently, and can carry more information.

Now vocational College Students are almost born after 90's, are the Internet's "indigenous people" and the network is an essential part of their lives. They can skillfully use the Internet to find information, watch videos, play games, chat and listen music, so they already have good online learning skills. The abilities of students' proficiency in the use of the network could reduce the online learning difficulties for them.

Necessity of Personalized Recommendation. Abundant online learning resources provide more learning options for learners. The Ethernet make learning resources develop rapidly, so it is difficult to avoid the resource quality reduction. For beginners, yet they do not build up their expertise knowledge architecture, so it is difficult to find suitable professional information for their own interests. In addition, online learning resources of MOOC courses are for all learners, they are only designed for the courses knowledge, not taken the students' professional structure, learning condition, learning situation and learning scenes into consideration, importantly they are unable to help students develop a personalized learning plan.

In this case, personalized recommendation is an effective method based on big data [4]. With the powerful data collection, classification and extraction technologies, variety of "key words" are given based on past learning data for the students, then some resources are recommended using these keywords to help students develop a learning plan and improve learning efficiency, so this can make these students online learning more effective.

\section{Personalized Recommendation Model for Vocational Student Online Learning}

Through the above analysis, because the online learning resources have some limitations and diversity and many knowledge points, to design personalized recommended mobile learning models is very important and necessary based on the characteristics of higher vocational education and learning [5].

Learning Model of Personalized Recommendation. Personalized learning is a learning model for students' specific learning needs, interests and cultural backgrounds; the goal is to enable students to determine their own learning plans, progress and strategies. The demands for personalized learning already exist, with the development of computer technologies and the recommendation algorithms, personalized learning projects gradually expand and develop rapidly, such as: TEx, Total Educational Experience at University of Texas, E2Coach technical at University of Michigan, all of these provide students with educational content and recommended resources by themselves information, adjust the courses according to the student's preferences and abilities also.

Personalized learning Recommendation is prerequisites for personalized learning; it is an effective method for "information overload". It builds a binary relationship between students and teaching resources using students' existing selection processes or similar relationship to mine the potential information that students interested in. These personalized recommendation systems push resources for students with different characteristics.

The Basic Framework for Personalized Recommendation Model. The basic framework for personalized learning recommendation model is shown in Figure 1. 


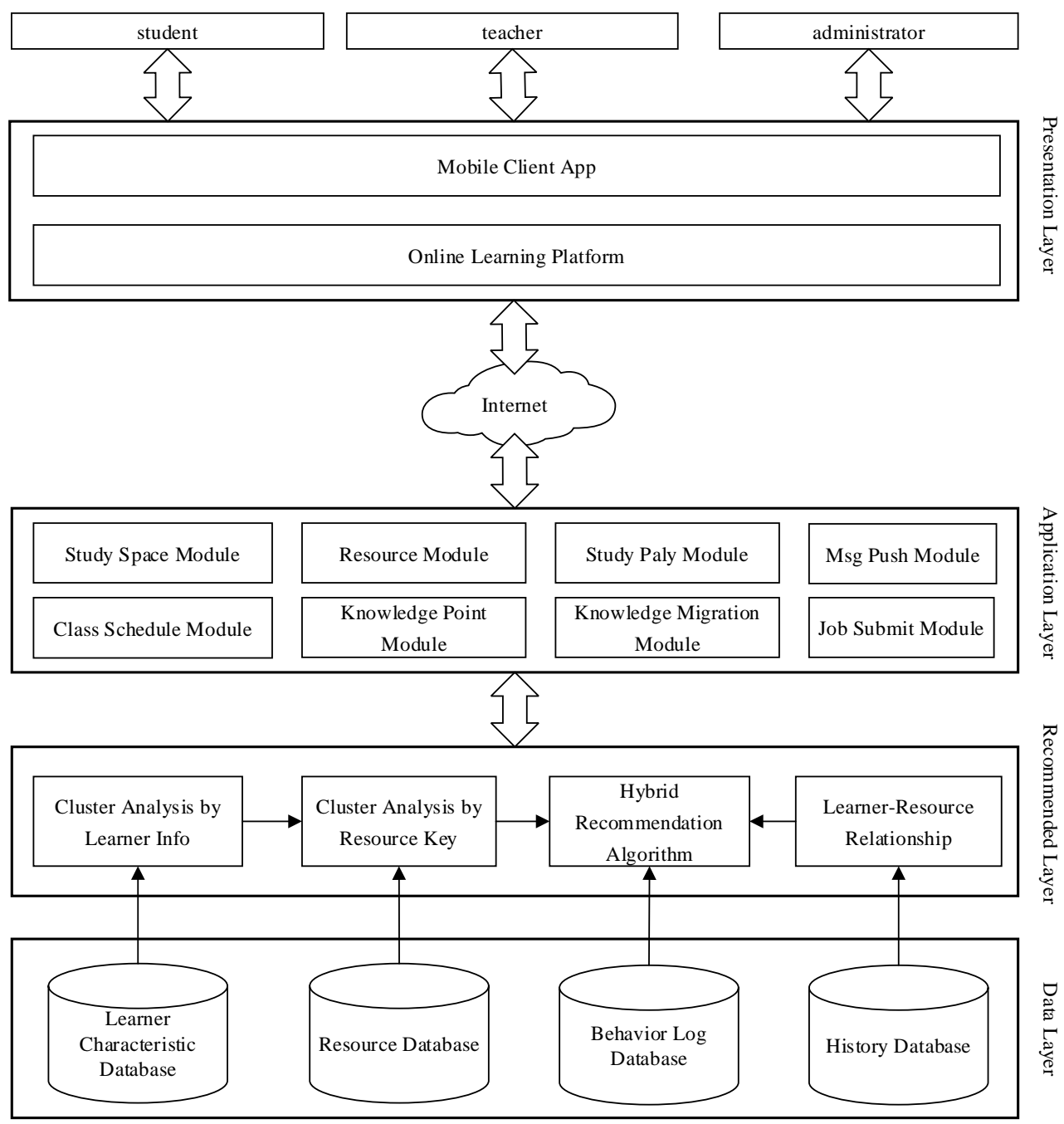

Fig. 1. Basic framework of personalized learning recommendation model.

\section{1) Data Layer}

The first step for personalized recommendation is to collect raw data of recommendation related to the object. Personalized recommendation mainly collects data for online learning including students and teaching resources such as: basic characteristics of students' demographics, resource database, learning behavior and history log database. There is no publicly available data sets can be adopted. The basic characteristics of students can be obtained from educational systems of higher vocational colleges, students' learning habits and behaviors data can be collected through questionnaires initially and conducted by analyzing web feedback logs, so more and more accurate sample eigenvalues can be gotten increasingly. Teaching resources can be gotten or independent collected from the national resource repository, MOOC course websites and so on, these are stored in a campus network data center.

\section{2) Recommendation Layer}

After recommended object data is collected completely, the data need to be handled, which is a data mining process. The results are input into recommendation systems as basic data for the recommendation Algorithm. The learners have been polymerized and classified according to the basic information in learner characteristics database. According to tags in resources database, these resources are aggregated and classified, so the eigenvalues for information relationship can be made among teaching resources, the "cold start" problems can be solved also. In this layer, the recommendation systems can build user-resource relationships and characteristics of learners personalized information using histories of learner behaviors in web-log database.

Recommendation algorithms are the kernel part of the recommendation systems. Using collaborative filtering algorithm [6], this system can deal with students learning traces and learning 
records, the resources what students want to get or look up usually can be obtained. These learning resources can be integrated based on data relationships and recommend to students.

3) Application Layer

Application layer is the main part of the recommendation model for personalized learning system, all services for online learning are encapsulated in this layer. Application layer deals with presentation layer request data. The number of modules in online learning platform depends on the student's learning needs, so most function modules can be customized by analyzing the learner demands such as: learning space, learning resources, study plans, course management, knowledge management, job submission, message push and so on to meet students' individual requirements.

4) Presentation Layer

The presentation layer is interactive interface between users and the online learning system. The result that be got from application layer presents to students in this online platform; meanwhile the system pushes teaching resources into students' learning logs by feedback. This way can help students to expand and transfer their professional knowledge. This system can recommend learning plans for students and help them manage their learning space.

\section{Conclusion}

Online learning recommendation system can be used to solve the traditional learning system problems. The E-learning systems are not to replace traditional classrooms but they can be used to complement the online learning process in our higher vocational colleges. This paper has provided a general overview of e-learning system architecture. The paper has discussed the personalized learning recommendation model and the four layers of E-learning system based network architecture. It also described these functions in every layers of this system. It can be applied to any higher education system using this model architecture.

\section{Acknowledgements}

This work was financially supported by the Jiangsu Second Vocational Education Research Foundation (zzz23).

\section{References}

[1] Jethro, O. Oludare, A. M. Grace and A. K. Thomas: E-Learning and its effects on teaching and learning in a global age. International Journal of Academic Research in Business and Social Sciences Vol. 2 (2012), p. 203-210.

[2] L. Breslow, D. E. Pritchard, J. Deboer, G. S. Stump, A. D. Ho, D. T. Seaton: Studying learning in the worldwide classroom: Research into edX's first MOOC. Research \& Practice in Assessment Vol. 8 (2013), p. 13-25.

[3] R. Sikka, A. Dhankhar and C. Rana: A survey paper on e-learning recommender system. International Journal of Computer Applications Vol. 47 (2012), p. 27-30.

[4] M. Jovanovica, M. Vukicevica, M. Milovanovica and M. Minovica: Using data mining on student behavior and cognitive style data for improving e-learning systems: a case study. International Journal of Computational Intelligence Systems Vol. 5(2012), p. 597-610.

[5] Mustafa, Y. E. Ali and S. M. Sharif: An approach to adaptive e-learning hypermedia system based on learning styles (AEHS-LS): Implementation and evaluation. International Journal of Library and Information Science Vol. 3(2011), p. 15-28. 
[6] S. YE and J. HE: Research on Learning Material Recommendation Based on Collaborative Filtering Algorithm in Cooperative Learning. Computer Technology and Development Vol. 24(2014), p. 63-70. 